\title{
DAMPAK ERUPSI GUNUNG MERAPI TERHADAP KAWASAN TAMAN NASIONAL GUNUNG MERAPI (TNGM) DI DIY DANJAWATENGAH
}

\author{
Sugeng Widodo ${ }^{1}$, Sriwidodo ${ }^{2}$, rrham $^{2}$, Jangkung Handoyomulyo ${ }^{3}$ \\ ${ }^{1}$ Mahasiswa Pasca Sarjana Fakultas Pertanian UGM dan Peneliti Sosek pada BPTP Yogyakarta \\ ${ }^{2}$ Staf Pengajar Program Studi Ekonomi Pertanian Universitas Gajah Mada, \\ ${ }^{3}$ Peneliti Pada Pusat Studi Kependudukan dan Kebijakan (PSKK) UGM \\ E-mail: wsugeng2@yahoo.com
}

\begin{abstract}
The purpose of this study was to identify the influence of Merapi eruption on the value of the environment at Merapi TNGM region.Research carried out around the area oh Mount Merapi adjacent to protect forest area TNGM, covering 13 villages namely Kepuharjo, Glagaharjo Hargobinangun sub district, Cangkringan and Pakem Sleman District, Balerante, Tegalmulyo and Sideredjo, Kemalang sub district, Klaten District, Mranggen, Paten, Mangunsoko and Krinjing Villages, Dukun sub district, Magelang District and Tlogolele, Jrakah and Samiran Villages, Selo Sub District, Boyolali District. The samples used were 220 farmers using simple random sampling method. Studied the impact of Merapi eruption was the eruption in 2006 and most of the 2010 eruption. Environmental economic analysis by the method of Contingent Valuation Method (CVM) were used. The results showed that the eruption of Merapi significantly effected on based use value and existence value. Direct use value (dry trees to firewood, grasses and water consumption value) before and after eruption was 5.935 billions and billions 5.457 IDR per year whereas existence value (willining to pay andwilliningnes to accept value) was 223.90 millions and millions 230.16 IDR per year. The indirect use value (biodiversity, conservation and carbon storage value) on 1.51 billions IDR per year. Based on the total economic value (TotalEconomic Value) of protected forest TNGM, a decline of $0.93 \%$, TEV values before and after eruption was 7.67 billions and billions 7.20 IDR per year.
\end{abstract}

Keywords: Merapi eruption, TNGM, Social and Economic Value, Environment Economic, Total Economic Value

\begin{abstract}
Abstrak: Tujuan penelitian ini adalah untuk mengidentifikasi nilai lingkungan pada kawasan TNGM Merapi. Penelitian dilakukan sekitar kawasan Gunung Merapi berdekatan dengan kawasan hutan lindung TNGM, meliputi 13 desa, yaitu desa Kepuharjo, Glagaharjo Hargobinangun Kec.Cangkringan dan Pakem Kab. Sleman, Balerante, Tegalmulyo dan Sidorejo Kec. Kemalang Kabupaten Klaten, Desa Mranggen, Paten, Mangunsoko dan Krinjing Kec Dukun Kabupaten Magelang, serta Desa Tlogolele, Jrakah dan Samiran Kec Selo Kab Boyolali. Jumlah sampel yang digunakan 220 petani dengan menggunakan metode simple random sampling.Dampak erupsi Merapi yang diteliti adalah erupsi Merapi tahun 2006 dan sebagian erupsi tahun 2010.Digunakan analisis ekonomi lingkungan dengan metode Contingent Valuation Method (CVM).Hasil penelitian menunjukkan bahwa: erupsi Merapi berdampak nyata terhadapnilai manfaat langsung dan keberadaan TNGM. Nilai manfaat (kayu bakar, rumput-rumputan dan nilai konsumsi air) sebelum dan setelah erupsi masing-masing memberikan nilai manfaat ekonomi (economic value) sebesar Rp 5.935.742.769,00 dan Rp 5.456.829.837,00 per tahun dimana nilai WTP dan WTA masing masing sebesar 223.898.834,94 dan Rp 230.157.738,10 per tahun. Manfaat tidak langsung meliputi biodiversity, konservasi dan nilai cadangan karbondengan nilai sebesar Rp
\end{abstract}


1.510.247.377,18. Berdasarkan nilai ekonomi total (total economi value) dari hutan lindung TNGM, terjadi penurunan sebesar $0,93 \%$, nilai TEV sebelum dan sesudah erupsi adalah $\mathrm{Rp}$ 7.669.888.981,12 dan $\mathrm{Rp} 7.197 .234 .952,28$ per tahun.

Kata kunci : Erupsi Merapi, TNGM, WTP, WTA, TEV

\section{PENDAHULUAN}

Gunung Merapi merupakan salah satu gunung berapi yang paling aktif di dunia.Secara administrasi terletak pada empat kabupaten yaitu Klaten, Boyolali dan Magelang Provinsi Jawa Tengah serta Kabupaten Sleman, DIY. Pada tahun 2006 dan tahun 2010 terjadi erupsi Merapiyang menimbulkan dampak terhadap hampir semua sektor : pertanian, kehutanan, perikanan, pariwisata, pemukiman, infrastruktur yang berujung pada kerugian ekonomi bagi masyarakat umum dan khususnya masyarakat yang tinggal disekitar Merapi. Perbedaan yang nyata erupsi tahun 2006 terhadap erupsi tahun 2010 yaitu pada daya rusak yang ditimbulkan, pada erupsi tahun 2006 dominan kerusakan karena abu vulkanik yang menyebar hampir disemua kawasan Merapi, sedangkan lahar panas hanya sebagian yang merusak khusus di kawasan Kaliadem Kepuharjo dan Glagaharjo Kecamatan Cangkringan Kabupaten Sleman, serta sebagian kawasan Taman Nasional Gunung Merapi (TNGM). Sebaliknya erupsi Merapi tahun 2010, daya rusaknya sangat besar selain menimbulkan banyak kematian terhadap manusia, ternak dan satwa lainnya juga kerusakan lingkungan kawasan TNGM. Berdasarkan hasil analisis citra satelit rekaman bulan Mei-Juni 2006 dan peta rupabumi skala 1:25.000 erupsi Merapi memiliki sebaran abu vulkanik di Kabupaten Sleman +6.561 ha (BBSDL, 2006 dalam Widodo et al., 2006). Sebaran terbesar terjadi di bagian atas yakni pada penggunaan lahan diatas $700 \mathrm{~m} \mathrm{dpl}$ dengan luas sebaran abu vulkanik sebesar 4.767 ha, sedangkan untuk ketinggian tempat dibawah $700 \mathrm{~m}$ dpl luas sebaran abu vulkanik sebesar 1.794 ha (BBSDL, 2006).

Keputusan Menteri Kehutanan Nomor: SK 134/MENHUT-II/2004 tanggal 4 Mei 2004, perubahan fungsi Kawasan Hutan Lindung, Cagar, dan Taman Wisata Alam pada Kelompok Hutan Gunung Merapi menjadi TNGM. Letak TNGM pada koordinat $07^{\circ} 22^{\prime} 33^{\prime \prime}$ - $07^{\circ} 52^{\prime} 30^{\prime \prime}$ LS dan $110^{\circ} 15^{\prime} 00^{\prime \prime}$ - $110^{\circ} 37^{\prime} 30^{\prime \prime}$ BT. Luas totalnya adalah 6.410 ha, dimana 5.126,01 ha berada diwilayah Jawa Tengah dan $1.283,99$ ha di DIY. Terjadinya erupsi Merapi tahun 2010 menyebabkan penutupan lahan kawasan TNGM. Menurut Hoer (2011), berdasarkan hasil pengolahan citra (interpretasi), terdapat penutupan hutan lahan kering primer, hutan lahan kering sekunder, hutan tanaman, lahan terbuka, pertanian lahan kering, semak belukar, dan lautan pasir/medan lahar.

Menurut BKSDA DI Yogyakarta dan Fakultas Kehutanan UGM (2002), jenis-jenis tanah di wilayah TNGM adalah regosol, andosol, alluvial dan litosol, dengan tipe iklim di wilayah ini adalah tipe $\mathrm{C}$ menurut klasifikasi curah hujan Schmidt dan Ferguson. Berdasarkan laporan BKSDA DI Yogyakarta dan Fakultas Kehutanan UGM (2002) hidrologi wilayah Gunung Merapi merupakan sumber bagi tiga DAS (daerah aliran sungai), yakni DAS Progo di bagian barat; DAS Opak di bagian selatan dan DAS Bengawan Solo di sebelah timur. Keseluruhan, terdapat sekitar 27 sungai di seputar Gunung Merapi yang mengalir ke tiga DAS tersebut.

Manfaat lain selain material, di kawasan hutan lindung TNGM adalah tulang punggung sistem geohidrologi, berfungsi sebagai menara air penyedia kebutuhan air wilayah di sekitarnya. Air yang berada dan mengalir dari tubuhnya bukan hanya untuk komunitas di lerengnya, tetapi juga untuk masyarakat yang jauh darinya di tersebar di Yogyakarta, Magelang, Boyolali dan Klaten.

Gunung Merapi memiliki keaneka ragaman hewan (76 spesies) dan tumbuhan (43 famili), yang sebagian merupakan flora dan fauna langka. Kenakeragaman flora dan fauna tersebut tersebar di dalam Hutan Lindung (1.461 hektar), Hutan Wisata (131 hektar), Cagar alam (181 hektar) di wilayah DIY, dan hutan negara di wilayah Propinsi Jawa Tengah. Gunung Merapi merupakan benteng terakhir keanakeragaman hayati Yogyakarta dan sekitarnya. Kekayaan keaneka-ragaman hayati tersebut pula yang selama ini dimanfaatkan 
dengan baik masyarakat desa tertinggi untuk mencukupi kebutuhan pakan ternak dan kayu bakar.

Undang-undang nomor 24 tahun 1992, tentang penataan ruang, menetapkan bahwa perencanaan tata ruang dilakukan dengan mempertimbangkan:(1)keserasian, keselarasan, dan keseimbangan fungsi budidaya dan fungsi lindung, dimensi waktu, teknologi, dan sosial budaya (2) aspek pengelolaan secara terpadu berbagai sumberdaya, fungsi dan estetika lingkungan, serta kualitas ruang. Setiap gerak dan langkah perencanaan memerlukan data dasar, dan setiap data dasar memerlukan persyaratan yang mampu (1) memberi informasi yang jelas mengenai situasi saat ini; (2) menunjukkan proses-proses yang berlangsung saat ini; (3) mengemukakan proyeksi terhadap pembangunan dimasa yang akan datang. Berbagai data dan informasi kawasan Merapi hendaknya dapat memberikan gambaran tentang kejelasan:Aspek sosialbudaya, sebagai daya dukung keseimbangan sikap budaya masyarakat terhadap kawasan. Aspek ekonomi, sebagai daya dukung pemenuhan kebutuhan hidup keseharian masyarakat kawasan. Aspek fisik lahan, sebagai daya dukung keseimbangan fisik lahan terhadap kemungkinan perubahan fungsi lahan dan Aspek lingkungan, sebagai daya dukung kerseimbangan lingkungan terhadap kemungkinan perubahan fungsi lingkungan. Berdasarkan latar belakang dampak erupsi Merapi terhadap kawasan Taman Nasional Gunung Merapi tersebut, maka penelitian ini dilakukan dengan tujuan untuk mengetahui dampak erupsi Merapi terhadap nilai ekonomi total (TEV) lingkungan kawasan Taman Nasional Gunung Merapi (TNGM).

\section{METODE PENELITIAN}

\section{Kerangka Teoritik}

Penelitian menggunakan pendekatan teknik nilai pasar dan teknik survei untuk mengetahui manfaat atau nilai social (social value) dan nilai ekonomi total (Total Economic Value) terhadap keberadaan kawasan hutan lindung Merapi (TNGM).Secara kualitatif dapat dijelaskan bahwa penelitian diawali dengan fenomena yang terjadi karena erupsi Gunung Merapi.Dampak yang ditimbulkan selain menimbulkan kematian bagi manusia, ternak, kerusakan dan kerugian terhadap sektor pertanian, perikanan, perkebunan, infrastruktur, pemukiman, wisata dan kerusakan pada kawasan hutan lindung TNGM.

Salah satu sumberdaya yang menjadi perhatian di kawasan hutan lindung TNGM adalah manfaat sangat besar bagi kehidupan manusia, menjaga ekosistem, menekan pemanasan global, bernilai ekonomi tinggi bagi kelangsungan hidup hajat orang banyak. Oleh karena itu diperlukan suatu analisis yang hasilnya dapat dipergunakan oleh pemerintah pusat atau daerah dalam menentukan kebijakan dalam upaya pengelolaan potensi kawasan TNGM yang dapat memberikan manfaat bagi semua pihak.

Teori ekonomi lingkungan digunakan dalam mengidentifikasi manfaat langsung dari TNGM meliputi pemanfaatan kayu bakar/ranting, rumput-rumputan dan air bagi rumahtangga petani. Sedangkan untuk pemanfaatan tidak langsung meliputi nilai karbon (carbon storage), keanekaragaman hayati (biodiversity), menekan konservasi tanah dan air. Sedangkan nilai option valuel keberadaan kawasan TNGM ini didekatkan berdasarkan nilai ekonomi, sosial budaya dan kelestarian di kawasan ini.Terdapat dua variabel pokok yaitu manfaat sosial (social benefit) dan variable biaya sosial (social cost). Untuk manfaat sosial terkandung komponen manfaat sosial secara ekonomi dalam penggunaan langsung (direct use value) maupun penggunaan tidak langsung (indirect use), kemudian nilai keberadaan (existence value).Analisis before dan after digunakan untuk melihat dampak erupsi Merapi

\section{Lokasi, Penentuan Sampel dan Analisis Data}

Penelitian dilaksanakan di kawasan hutan lindung TNGM yaitu Desa Balerante, Tegalmulyo dan Sidorejo Kecamatan Kemalang Kab Klaten, Desa Jrakah, Samiran dan Tlogolele Kecamatan Selo Kabupaten Boyolali, Desa Mranggen, Paten, Mangunsoko dan Kerinjing Kecamatan Dukun Kabupaten Magelang dan Desa Kepuharjo, Glagaharjo dan Hargobinangun Kecamatan Cangkringan Kabupaten Sleman. Berdasarkan pendekatan zona, coverage wilayah hutan dikawasan lokasi 
penelitian ini 39,10\% dari keseluruhan luas TNGM yaitu sebesar 1.728,70 Ha.

Data yang digunakan sebanyak 220 responden petani yang dipilih secara simple random sampling dengan sebaran sampel yang proporsional berdasarkan pewakil masingmasing kabupaten.Metode deskriptif digunakan sebagai survai normatif (normative survey) denganpendekatan before and after, yaitu membandingkan antara dampak sebelum dan sesudah erupsi Merapi.Teknik CVM (Contingen Value Methode) digunakan dalam memperoleh data lingkungan.Teknik wawancara untuk mengetahu kemampuan responden dalam mengetahui taksiran kerugian lingkungan dilakukan dengan pendekatan close-ended CVM dengan berusaha menggali responden mendapatkan tingkat kerugian yang diakibatkan erupsi. Pendekatan discrete choice untuk menanyakan kepada responden menerima atau menolak taksiran kerugian dari yang disampaikan enumerator yang sudah diestimasinya atau berdasarkan open ended responden menaksirnya sesuai dengan kondisi saat berlangsung (Bishop dan Heberlein, 1979).

Data aspek ekonomi lingkungan kawasan hutan lindung dengan pendekatan nilai ekonomi total terdiri dari :manfaatlangsung, manfaat tidak langsung, dan nilai keberadaan TNGM. Nilai manfaat tidak langsung meliputi: nilai gudang karbon, keanekaragaman hayati (biodersivity), konservasi tanah dan konsumsi air. Nilai keberadaan (existance value) meliputi: nilai kumulatif dari nilai sosial dan budaya/kearifan lokal lingkungan sosialdengan pendekatan pada nilai kemampuan membayar dari masyarakat atau WTP (willining to pay)terhadap keberadaan kawasan hutan lindung serta kemauan masyarakat dalam menerima atau WTA (williningnes to accept) terhadap keberadaan TNGM di kawasan hutan lindung Merapi.Penjumlahan antara nilai WTA dan WTP merupakan nilai total dari keberadaan (existences value)

Analisis TEV digunakan untuk mengetahui nilai ekonomi total kawasan TNGM Nilai Ekonomi Total atau Total Economic Value (TEV),secara matematis dan teoritis, Nilai Ekonomi Total (TEV) dapat dijelaskan sebagai berikut (Munasinghe, 1993;
Turner.K.R,Pearce D and Ian Bateman, 1994 cit. Irham et. al.,2001) :

$$
\begin{aligned}
& \mathrm{TEV}=\mathrm{UV}+\mathrm{NUV} \\
& \mathrm{TEV}=(\mathrm{DUV}+\mathrm{IUV})+(\mathrm{OV}+\mathrm{BV}+\mathrm{EV})
\end{aligned}
$$

Keterangan:

$$
\begin{aligned}
& \mathrm{TEV}=\text { Nilai Ekonomi Total (Total } \\
& \text { Economic Value) } \\
& \mathrm{UV}=\text { Nilai penggunaan (Use value) } \\
& \text { NUV }=\text { Nilai non penggunaan (Non use } \\
& \text { value) } \\
& \text { DUV = Nilai Guna Langsung (Direct } \\
& \text { Use Value) } \\
& \text { IUV = Nilai Guna Tidak Langsung } \\
& \text { (Indirect Use Value) } \\
& \mathrm{OV}=\text { Nilai Pilihan (Option Value })^{* *} \\
& \mathrm{BV}=\text { Nilai Warisan (Bequest Value })^{* *} \\
& \mathrm{EV}=\text { Nilai Keberadaan (Existence } \\
& \text { Value) }
\end{aligned}
$$

Direct Use Value (DUV) atau nilai guna langsung :

1. Pemanfaatan kayu ranting/bakar dinilai dengan nilai uang pada harga yang berlaku

2. Pemanfataan rumput-rumputan dan hajauan pakan ternak dinilai uang/tenaga yang dialokasikan untuk mengambil rumput berdasarkan harga yang berlaku aktual

3. Pemanfaatan air untuk rumahtangga dan ternak dinilai berdasarkan pemanfaatan air dan disetarakan dengan harga air aktual yang berlaku

Indirect Use Value (IUV) merupakan nilai yang secara tidak langsung:

1. Nilai keanekaragaman hayati (biodiversity)

2. Nilai konservasi

3. Nilai karbon (Carbon Storage)

Keterangan : **) nilai pilihan dan nilai warisan tidak diperhitungkan dalam tulisan ini

Nilai manfaat tidak langsung (biodiversity, konservasi dan cadangan karbon) menggunakan nilai Jasa UU SDA no 15 tahun 2012 Kementrian Negara Lingkungan Hidup RI, hasil data terolah dari penelitian Asmaranto dan Juwono (2007), dan Subekti-Rahayu et al., 2004 ditabelkan dan diolah pada Tabel 1. 
Sugeng W., Sriwidodo., Irham., Jangkung H. : Dampak erupsi gunung merapi ......

Tabel 1.Berbagai Jenis Hutan dan Lahan Terhadap Nilai Konversi (US \$) per Ha/Tahun

\begin{tabular}{lccc}
\hline Jenis Hutan dan & Biodiversity & $\begin{array}{c}\text { Konservasi } \\
\text { US }(\$) \text { per Ha }\end{array}$ \\
\hline Hutan primer+sekunder & $9,45^{\mathrm{a}}$ & $37,95^{\mathrm{a}}$ & $5,00^{\mathrm{a}}$ \\
Lahan Terbuka & 0 & 0 & 0 \\
Pertanian Lahan Kering*) & $6,00^{\mathrm{b}}$ & $0,088^{\mathrm{b}}$ & $0,10^{\mathrm{c}}$ \\
Semak belukar & 0 & $3,79^{\mathrm{b}}$ & 0 \\
\hline
\end{tabular}

Sumber : Data sekunder (diolah), 2014

Keterangan:

a $\quad$ UU SDA Lingkungan Hidup 2012

$\mathrm{b} \quad=$ Asmaranto dan Juwono, 2007 nilai faktor CP (diolah)

${ }^{c}=$ Subekti Rahayu et al., 2004 dalamwww.worldagroforestry.org (diolah)

*) = Tanaman padi + palawija

Existence Value (EV) nilai keberadaan sumberdaya alam di kawasan TNGM merupakan nilai kumulatif dari kelestarian, ekonomi sosial dan budaya/kearifan lokal dengan pendekatan pada nilai WTP (willining to pay) dan nilai WTA (williningnes to accept) terhadap keberadaan TNGM

\section{HASIL DAN PEMBAHASAN}

\section{Manfaat Sosial dan Ekonomi}

Sebelum dilakukan perhitungan manfaat sosial dan nilai ekonomi, maka dilakukan perhitungan komponen-komponen yang membentuk nilai ekonomi total kawasan hutan lindung TNGM meliputi nilai-nilai tersebut baik sebelum maupun setelah erupsi Merapi, yaitu:

\section{Nilai Penggunaan Langsung TNGM di Kawasan Merapi}

\section{Manfaat kayu ranting/bakar}

Kayu yang dimaksud adalah ranting dan dahan yang tidak bermanfaat yang berada di kawasan hutan lindung yang diperhitungkan berdasarkan rerata pengambilan selama setahun per rumahtangga.Nilai manfaat kayu yang diambil diperhitungkan dengan harga aktual/pasar yang berlaku menjadi nilai rupiah per Rumahtangga petani/TH. Di Kawasan TNGM kayu ranting/bakar cukup banyak jenisnya antara lain sengon, manisrejo, akasia, dadap, mindi, suren dan bambuapus.

\section{Manfaat rumput rumputan}

Rumput yang dimanfaatkan adalah pohonpohonan, kolonjono, gajah.rumput teki, dan kaliandra. Masyarakat sekitar kawasan hutan lindung Merapi selain bertani juga banyak berternak khususnya sapi perah dan sapi potong. Seperti dalam penjelasan diatas bahwa responden adalah petani sekaligus sebagai peternak maka kebutuhan rumput cukup tinggi.Sebagian petani/peternak memanfaatkan rumput di kawasan hutan lindung, hal ini disebabkan kebutuhan pakan rumput dari lahan yang ditanami tidak mencukupi.

\section{Manfaat air}

Keberadaan hutan lindung yang terjaga dengan baik menjamin suplai air.Nilai manfaat air dapat dinilai rata-rata konsumsi air yang dimanfaatkan untuk kebutuhan sehari-hari. Dalam perhitungan ini masih terbatas pada nilai air untuk konsumsi rumah tangga dan kebutuhan rata-rata untuk ternak sedangkan untuk kebutuhan air untuk lahan tidak diperhitungkan

Berdasarkan pemanfaatan sosial secara langsung ketiga komponen kayu bakar, rumputrumputan dan air untuk rumahtangga dan ternak disajikan pada tabel 2 .

Nilai kayu bakar bervariasi antar lokasi, rerata nilai kayu bakar sebelum erupsi sebesar Rp 91,65557 juta, namun setelah erupsi menurun sebesar 20,55\% menjadi Rp 76,02909 juta rupiah. Penurunan pemanfaatan kayu bakar disebabkan karena sebagian kawasan TNGM belum pulih dari dampak erupsi akibat kebakaran dan timbunan pasir dan lahar, sehingga masyarakat hanya mengambil yang terdekat saja.Pengambilan kayu ranting terbanyak di Desa Paten dan Sidorejo, hal ini berkait dengan kedekatan lokasi tempat tinggal dengan kawasan TNGM. 
Tabel 2. Nilai Kayu Bakar, Rumput-rumputan dan Manfaat Air di Kawasan TNGM Sebelum dan Setelah Erupsi Merapi

\begin{tabular}{|c|c|c|c|c|c|c|}
\hline \multirow[t]{4}{*}{ Lokasi } & \multicolumn{6}{|c|}{ Nilai Rataan Potensial per Lokasi (Rp/Th) } \\
\hline & \multicolumn{2}{|c|}{ Kayu Bakar } & \multicolumn{2}{|c|}{ Rumput-rumputan } & \multicolumn{2}{|c|}{ Konsumsi Air } \\
\hline & Before & After & Before & After & Before & After \\
\hline & \multicolumn{6}{|c|}{--------------------------------(x1000) -------------------------------------- } \\
\hline \multicolumn{7}{|l|}{ Klaten } \\
\hline Balerante & $62.888,43$ & $24.493,39$ & $620.940,50$ & $601.080,99$ & $15.008,07$ & $13.400,06$ \\
\hline Sidorejo & $251.662,60$ & $203.619,39$ & $779.170,64$ & $779.170,64$ & $69.461,21$ & $62.018,94$ \\
\hline Tegalmulyo & $99.639,89$ & $95.983,38$ & $444.631,58$ & $444.631,58$ & $21.692,56$ & $19.368,36$ \\
\hline \multicolumn{7}{|l|}{ Magelang } \\
\hline Mranggen & $23.024,25$ & $17.481,38$ & $170.550,00$ & $93.802,50$ & $67.977,82$ & $60.694,48$ \\
\hline Paten & $524.774,25$ & $478.700,75$ & $314.864,55$ & $298.452,60$ & $39.206,48$ & $35.005,78$ \\
\hline krerinjing & $45.905,78$ & $38.029,79$ & $166.971,04$ & $166.971,04$ & $68.274,96$ & $60.959,79$ \\
\hline Mangunsoko & $13.338,37$ & $11.382,08$ & $98.703,97$ & $98.703,97$ & $72.232,51$ & $64.493,31$ \\
\hline \multicolumn{7}{|l|}{ Sleman } \\
\hline Glagaharjo & $16.094,12$ & $6.437,65$ & $385.668,71$ & $379.726,51$ & $81.555,60$ & $72.817,50$ \\
\hline Kepuharjo & $66.666,67$ & $66.666,67$ & $436.666,67$ & $396.666,67$ & $46.951,50$ & $41.920,98$ \\
\hline Hargobinagun & $43.367,35$ & $18.503,40$ & $400.598,64$ & $377.284,35$ & $53.164,44$ & $47.468,25$ \\
\hline \multicolumn{7}{|l|}{ Boyolali } \\
\hline Samiran & $21.798,37$ & $10.899,18$ & $101.483,51$ & $74.598,86$ & $70.755,08$ & $63.174,18$ \\
\hline Jrakah & $8.362,31$ & $4.181,16$ & $119.162,98$ & $119.162,98$ & $39.498,87$ & $38.472,92$ \\
\hline Tlogolele & $14.000,00$ & $12.000,00$ & $35.000,00$ & $35.000,00$ & $24.028,51$ & $23.404,39$ \\
\hline Total & 1.191 .522 & 988.378 & 4.074 .413 & 3.865 .253 & 669.808 & 603.199 \\
\hline Rerata & $91.655,57$ & $76.029,09$ & $313.416,37$ & $297.327,13$ & $51.523,66$ & $46.399,92$ \\
\hline Persentase(\%) & & $(20,55)$ & & $(5,41)$ & & $(11,04)$ \\
\hline
\end{tabular}

Sumber: Data primer, 2014 diolah menggunakan excel versi 2007

Tabel 3. Nilai Kayu Bakar, Rumput-rumputan dan Manfaat Air di Kawasan TNGM Sebelum dan Setelah Erupsi Merapi

\begin{tabular}{lcccc}
\hline \multirow{2}{*}{\multicolumn{1}{c}{ Uraian }} & \multicolumn{2}{c}{ Nilai Rataan Potensial TNGM } & \multirow{2}{*}{ t-hitung } & \multirow{2}{*}{ Sig } \\
\cline { 2 - 3 } & \multicolumn{2}{c}{ Before } & After & \\
\cline { 2 - 3 } & $91.655 .568,77$ & $76.029 .093,15$ & $3,212^{* * *}$ & 0,007 \\
Kayu ranting/bakar & $313.416 .366,85$ & $297.327 .128,92$ & $2,575^{* *}$ & 0,024 \\
Rumput-rumputan & $51.523 .662,00$ & $46.399 .919,23$ & $6,425^{* * *}$ & 0,000 \\
\hline Air untuk RT dan Ternak & &
\end{tabular}

Sumber: Data primer diolah dengan menggunakan SPSS versi 20 (2014)

Keterangan: $* * *=$ signifikan pada $\alpha: 1 \%$, dan $* *$ signifikan pada $\alpha: 5 \%$

t-tabel pada $\alpha: 1 \%=2,6809 ; \alpha: 5 \%=1,7822 ;$ dan pada $\alpha: 10 \%=1,3562$

Berdasarkan perhitungan, nilai total kayu bakar yang diperoleh dikawasan TNGM sebelum erupsi adalah $\mathrm{Rp} 1.191 .522 .000$,- $\operatorname{per} / \mathrm{TH}$, sedangkan setelah erupsi Merapi turun sebesar 20,55\%menjadi Rp988.378.000,-.Berdasarkan uji t pada rataan nilai potensial kayu bakar di TNGM sebelum dan setelah erupsi sangat signifikan pada $\alpha: 1 \%$, nilai Sig $<0,01$ seperti yang tertera pada tabel 2 . Hal ini menunjukkan bahwa terjadinya erupsi Merapi berdampak nyata terhadap pemanfaatan nilai kayu total di kawasan TNGM. Perbedaan ini disebabkan karena setelah erupsi cenderung masyarakat dalam pemanfaatan kayu bakar menurun karena kondisi lokasi TNGM masih mengalami kerusakan dan belum sepenuhnya terjadi recovery seperti sebelum erupsi Merapi terjadi.

Nilai rumput-rumputan yang dimanfaatkan petani di kawaan TNGM relative cukup besar.Masyarakat lebih senang mengambil rumput-rumput dikawasan TNGM dibandingkan dengan menanam rumput dilahannya. Nilai total rumput-rumputan yang diambil dikawasan TNGM sebelum erupsi Merapi sebesar Rp 4.074.413.000/TH., namun setelah erupsi pengambilan rumput menurun sebesar 5,41\% menjadi Rp 3.865.253/TH dengan rata-rata nilai manfaat rumput sebelum erupsi Rp 313.416.370/TH dan setelah erupsi menurun menjadi Rp 297.327.130/TH. 
Berdasarkan uji t pemanfaatan rumputrumputan di kawasan TNGM signifikan pada $\alpha: 5 \%$, hal ini menunjukkan bahwa dampak erupsi berpengaruh terhadap nilai rumput yang diambil di kawasan TNGM. Selain itu perbedaan ini disebabkan karena populasi ternak sapi perah dan sapi potong menurun, sehingga kebutuhan rumput menurun pula, disamping itu karena kerusakan yang ditimbulkan menyebabkan sebagian rumputrumputan terbakar dan mati sehingga jumlah rumput-rumputan dikawasan TNGM secara kumulatif menurun. Penurunan populasi ternak sapi perah dari awal sebelum erupsi tahun 2006 dengan rerata pemilikan 2,56 ekor per RT peternak, dan setelah erupsi tahun 2010 menjadi 2,42 ekor per RT peternak (Widodo et al., 2014). Hal ini didukung pula dari data BPS (2011), bahwapopulasi sapi di kawasan Merapi menurun antara 2,22\%-40,47\% dari tahun 2007 s.d tahun 2010. Penurunan populasi ini karena erupsi Merapi tahun 2006 dan tahun 2010 menyebabkan kematian ternak, dan sebagian besar juga dijual karena tidak mau merugi.

Keberadaan hutan lindung yang terjaga dengan baik menjamin suplai air.Nilai manfaat air dapat dinilai rata-rata konsumsi air yang dimanfaatkan untuk kebutuhan sehari-hari.Nilai manfaat air yang digunakan untuk rumahtangga dan ternak sebelum erupsi sebesar $\mathrm{Rp}$ 669.808.000/TH dan setelah erupsi menurun sebesar 11,04\% menjadi Rp 603.199.000/TH. Perbandingan sebelum dan setelah erupsi, berdasarkan uji $\mathrm{t}$ pada taraf $\alpha: 1 \%$ sangat signifikan, hal ini menunjukkan bahwa erupsi selain berdampak terhadap nilai kayu bakar, rumput-rumputan juga terhadap nilai air (Tabel 2). Penurunan pemanfaatan air disebabkan sebagian masih mengalami kerusakan di saluran air, sumur, dam (Desa Kepuharjo, Sleman), hal ini yang menyebabkan penurunan dan perbedaan pemanfaatan air untuk rumahtangga dan ternak.

\section{Nilai Guna Tidak Langsung}

Nilai guna tidak langsung merupakan manfaat tidak langsung kawasan hutan lindung TNGM meliputi nilai keanekaragaman hayati, konservasi dan penyerapan karbon. Pendekatan analisis berdasarkan UU SDA No 15 dalam Kementrian Lingkungan Hidup dan Kehutanan (2012), Asmaranto dan Juwono (2007) dan Subekti-Rahayu et al., (2004).

\section{Nilai Keanekaragaman Hayati (Biodiversity)}

Nilai biodiversity total kawasan TNGM adalah Rp 269.707.837,60/TH, kontribusi besar pada hutan primer dan sekunder Rp 266.954.533,84, sedangkan untuk lahan terbuka dan semak belukar bernilai nol artinya tidak memberikan kontribusi terhadap nilai biodiversity. Sedangkan terhadap lahan terbuka yang dimanfaatkan untuk pertanian tanaman pangan (padi dan palawija) memberikan kontribusi nilai biodiversity sebesar Rp 2.753.303,76 per $\mathrm{Ha} / \mathrm{TH}$ (tabel 4).

Menurut Kim et al., (2002) nilai jasa dan fungsi ekosistem kawasan hutan primer untuk biodiversity adalah \$ 41 US. Perbedaan nilai jasa dan fungsi biodiversity yang cukup besar ini karena Kim et al., 2002 menilai kawasan hutan primer yang masih perawan dan mengkombinasikan dari berbagai hutan primer di kawasan Asia Pasifik.

Tabel 4. Nilai Biodiversity di Kawaan Hutan Lindung TNGM Merapi

\begin{tabular}{|c|c|c|c|c|c|}
\hline \multirow{2}{*}{ No } & \multirow{2}{*}{ TNGM } & \multirow{2}{*}{ Luas (Ha) } & \multirow{2}{*}{ Biodiversity } & \multicolumn{2}{|c|}{ Nilai Total/TH } \\
\hline & & & & US \$ & $\mathrm{Rp}$ \\
\hline 1 & Berhutan & 2906,89 & $9,45^{\mathrm{a}}$ & $27.470,11$ & $266.954 .533,84$ \\
\hline 2 & Lahan Terbuka & 2453,09 & 0,00 & 0,00 & \\
\hline 3 & Lahan Kering & 47,22 & $6,00^{\mathrm{b}}$ & 283,32 & $2.753 .303,76$ \\
\hline 4 & Semak belukar & 737,2 & 0,00 & 0,00 & \\
\hline & Total TNGM & $6.144,40$ & & $27.753,43$ & $269.707 .837,60$ \\
\hline
\end{tabular}

Sumber: Data primer diolah, 2014

Keterangan:

Nilai US (\$) biodiversity = perkalian antara luas (ha) dengan nilai biodiversity

Nilai US \$ terhadap rupiah Rp 9.718,00,-

a $\quad=$ UU SDA I no 15 Kementrian Lingkungan Hidup, 2012

= Asmaranto dan Juwono, 2007 (diolah) 
Sugeng W., Sriwidodo., Irham., Jangkung H. : Dampak erupsi gunung merapi ......

Tabel 5. Nilai Konservasi di Kawaan Hutan Lindung TNGM Merapi

\begin{tabular}{lrrrr}
\hline \multirow{2}{*}{ TNGM } & \multirow{2}{*}{ Luas (Ha) } & \multirow{2}{*}{$\begin{array}{c}\text { Konservasi } \\
\text { (US \$/ha/th) }\end{array}$} & \multicolumn{2}{c}{ Nilai Total Konservasi per Tahun } \\
\cline { 5 - 5 } Hutan & & & & \multicolumn{1}{c}{ Up } \\
primer+sekunder & 2906,89 & 37,95 & $110.316,48$ & $1.072 .055 .508,91$ \\
Lahan Terbuka & 2453,09 & 0 & - & \\
Lahan Kering & 47,22 & 0,088 & 4,16 & $40.381,79$ \\
Semak belukar & 737,2 & 3,79 & $2.793,99$ & $27.151 .975,38$ \\
Total & 6144,4 & & $113.114,62$ & $1.099 .247 .866,08$ \\
\hline
\end{tabular}

Sumber: Data primer diolah, 2014

Keterangan:

Nilai total konservasi= perkalian antara luas (ha) dengan nilai konservasi

Nilai US \$ terhadap rupiah Rp 9.718,00,-

a $\quad$ UU SDA I no 15 Kementrian Lingkungan Hidup, 2012

$=$ Asmaranto dan Juwono, 2007 (diolah)

Tabel 6. Nilai Karbon di Kawaan Hutan Lindung TNGM Merapi

\begin{tabular}{lrrrr}
\hline \multirow{2}{r}{ TNGM } & \multirow{2}{*}{ Luas (Ha) } & Karbon $($ US & \multicolumn{2}{c}{ Nilai Total per tahun } \\
\cline { 4 - 5 } & & & dalam US \$ & dalam $\mathrm{Rp}$ \\
\hline Hutan & & & & \\
primer+sekunder & 2906,89 & $5,00^{\mathrm{a}}$ & $14.534,45$ & $141.245 .785,10$ \\
Lahan Terbuka & 2453,09 & 0 & 0 & 0 \\
Lahan Kering & 47,22 & $0,10^{\mathrm{c}}$ & 4,72 & $45.888,40$ \\
Semak belukar & 737,2 & 0 & 0 & 0 \\
$\quad$ Total & 6144,4 & & $14.539,17$ & $141.291 .673,50$ \\
\hline
\end{tabular}

Sumber: Data primer diolah, 2010

Keterangan: Nilai total karbon = perkalian antara luas (ha) dengan nilai karbon

Nilai US \$ terhadap rupiah Rp 9.718,00,-

a $=$ UU SDA I no 15 Kementrian Lingkungan Hidup dan Kehutanan, 2012

c $\quad=$ Subekti Rahayu et al., 2004 dalamwww.worldagroforestry.org (diolah)

\section{Konservasi Tanah(Soil Conservation)}

Jasa-jasa konservasi tanah dari hutan lindung antara lain untuk mencegah erosi, mencegah banjir dan meningkatkan kesuburan tanah. Hal ini disebabkan di daerah tropika basah curah hujan relatif tinggi sehingga potensi bahaya erosi tanah dan banjir sangat besar.

Merujuk Tabel 5, nilai konservasi hutan primer dan sekunder sebesar Rp 1.072.055.508,91/TH, sedangkan kawasan hutan lindung yang dimanfaatkan oleh masyarakat untuk budidaya di lahan kering tanpa melakukan tindakan konservasi lahan sangat rendah karena luasan dan nilai konversi konservasi memang rendah (dinilai $0,088 \$ / \mathrm{ha}$ ) sehingga didapatkan hasil sebesar Rp 40.381,79 per ha. Semak berukar memberikan kontribusi terhadap total nilai konservasi cukup besar yaitu Rp 27.151.975,38,- per tahun. Hal ini disebabkan dengan permukaan tanah tertutup rapat oleh semak belukar menjadikan mampu menahan tanah dari erosi karena curah hujan.Menurut Sasmitawidjaja (2004)nilai jasa dan fungsi ekosistem kawasan hutan lindung untuk mencegah erosi adalah \$245/tahun dan konservasi air sebesar US \$ 9 / tahun.Menurut BNPB (2011)dari luas 6.400 ha kawasan TNGM. akibat erupsi Merapi tahun 2010 yang mengalami kerusakan hutan adalah sebesar 1.128 ha atau $17.60 \%$ dari total areal TNGM sebagian besar di kawasan Resort Cangkringan dan Resort Pakem-Turi Kabupaten Sleman dengan estimasi kerugian yang ditimbulkan masing-masing sebesar Rp 5.755.000.000 dan Rp 157.000.000.000.-

\section{Nilai Gudang Karbon (Carbon Storage Value)}

Areal kawasan hutan lindung merupakan penyerap karbon cukup besar, hal ini berkaitan erat dengan pemanasan global maka kelestarian hutan sangat penting dalam menyerap karbon. Berdasarkan pendekatan yang sama dalam perhitungan nilai karbon disajikan pada Tabel 6 . 
Merujuk Tabel 6, nilai penyimpan karbon hutan primer dan sekunder sebesar Rp 141.245.785,10/TH, untuk lahan terbuka dan semak belukar bernilai nol karena tidak menyerap karbon, sedangkan untuk lahan kering yang dimanfaatkan oleh masyarakat setempat untuk budidaya padi dan palawija memberikan kontribusi rendah.Menurut Rolan dan Woon. 1993 dalam Kimet al., (2002) nilai 1 ton $\mathrm{C}=10 \$$, sedangkan berdasarkan The World Bank (2001) dalam Mantung et al., 2010 harga karbon sebesar US 5.8 per ton $\mathrm{CO}_{2}$. Hasil penelitian Mantung et al.. (2010). harga serapan karbon sebesar US $\$ 4.57$ per ton di kawasan hutan lindung Pinus Mercussi.

Berdasarkan data Balai Taman Nasional Gunung Merapi tahun 2011 dalam Anggana AF (2011), jenis tumbuhan paling dominan untuk tingkat pohon di TNGM adalah Pinus Merkusii dan Accacia decurens. tanamanturi-turi (Lithocarpus sp)dan Pecingpecing (Quercus sp), pakis dan paku banyak yang tumbuh hingga ketinggianpohon $15 \mathrm{~m}$.

\section{Nilai Keberadaan (Existence Value)}

Pendekatan nilai keberadaan TNGM sebagai sumber ekonomi, sosial budaya (kearifan lokal), pengendali lingkungan dan kelestarian.Penilaian keberadaan TNGM dari sisi ekonomi dan pengendali lingkungan tidak dimasukkan dalam nilai keberadaan ini karena sudah diperhitungkan tersendiri pada nilai manfaat langsung yaitu kayu bakar dan rumputrumputan. Sedangkan sebagai pengendali lingkungan dalam hal ini menahan erosi sebagai salah satu fungsi hutan yaitu nilai konservasi telah perhitungkan tersendiri

Berdasarkan perhitungan tingkat kesediaan membayar, menerima dan dari fungsi keberadaan TNGM serta nilai gabungan WTP dan WTA dari fungsi nilai sosial budaya, dan kelestarian disajikan pada Tabel 7.

Merujuk pada Tabel 7, tingkat kesediaan membayar sebelum dan setelah eruspsi Merapi meningkat dari rerata $\mathrm{Rp}$ 4.452.222,27 menjadi Rp 4.691.440,86, demikian pula kesediaan menerima meningkat setelah erupsi. Nilai WTA sebelum dan setelah erupsi Merapi lebih tinggi dibandingkan dengan nilai WTP nya. Hal yang rasional bahwa secara umum kecenderungan dari masyarakat untuk menerima (WTA) lebih besar dibandingkan dengan kesediaan membayar (WTP) dari aspek dan obyek yang sama. Berdasarkan penelitian sebelumnya dengan membandingkan nilai WTP dan WTA maka nilai WTA hampir selalu lebih besar dibandingkan dengan WTP.

Tabel 7. Nilai Kesediaan Membayar, Menerima dan Nilai Total Keberadaan TNGM sebelum dan Setelah Erupsi Merapi

\begin{tabular}{lrrrrrr}
\hline \multirow{2}{*}{ Lokasi } & \multicolumn{2}{c}{ Kesediaan membayar $(\mathrm{Rp})$} & \multicolumn{2}{c}{ Kesediaan menerima $(\mathrm{Rp})$} & \multicolumn{2}{c}{ Nilai Sosbud+lingk Lestari } \\
\cline { 2 - 7 } & \multicolumn{2}{c}{ WTP } & \multicolumn{2}{c}{ WTA } & \multicolumn{2}{c}{ WTP+WTA } \\
\cline { 2 - 7 } & \multicolumn{1}{c}{ before } & \multicolumn{1}{c}{ after } & \multicolumn{1}{c}{ before } & \multicolumn{1}{c}{ after } & \multicolumn{1}{c}{ aftere } \\
\hline Balerante & $2.910 .300,00$ & $4.342 .443,50$ & $9.456 .250,00$ & $10.012 .500,00$ & $12.366 .550,00$ & $14.354 .943,50$ \\
Sidorejo & $4.071 .354,55$ & $4.284 .388,59$ & $13.822 .500,00$ & $14.660 .227,27$ & $17.893 .854,55$ & $18.944 .615,86$ \\
Tegalmulyo & $2.171 .700,00$ & $2.296 .245,00$ & $8.312 .500,00$ & $8.787 .500,00$ & $10.484 .200,00$ & $11.083 .745,00$ \\
Mranggen & $1.758 .918,33$ & $2.634 .739,09$ & $9.302 .727,27$ & $9.385 .418,18$ & $11.061 .645,60$ & $12.020 .157,27$ \\
Paten & $5.386 .500,00$ & $6.091 .875,00$ & $11.400 .000,00$ & $11.501 .816,25$ & $16.786 .500,00$ & $17.593 .691,25$ \\
Krerinjing & $7.757 .440,00$ & $7.830 .036,36$ & $19.186 .181,82$ & $19.704 .727,27$ & $26.943 .621,82$ & $27.534 .763,64$ \\
Mangunsoko & $8.396 .559,82$ & $8.438 .156,36$ & $17.622 .181,82$ & $17.878 .318,18$ & $26.018 .741,64$ & $26.316 .474,55$ \\
Glagaharjo & $4.636 .760,00$ & $4.636 .760,00$ & $20.830 .909,09$ & $20.957 .552,73$ & $25.467 .669,09$ & $25.594 .312,73$ \\
Kepuharjo & $2.704 .014,55$ & $2.704 .014,55$ & $6.000 .000,00$ & $6.036 .349,09$ & $8.704 .014,55$ & $8.740 .363,64$ \\
Hargobinagu & $5.067 .777,27$ & $5.067 .777,27$ & $22.677 .613,64$ & $22.718 .181,82$ & $27.745 .390,91$ & $27.785 .959,09$ \\
Samiran & $7.578 .796,91$ & $7.336 .051,35$ & $10.573 .309,09$ & $10.620 .511,36$ & $18.152 .106,00$ & $17.956 .562,72$ \\
Jrakah & $3.275 .515,80$ & $3.137 .863,40$ & $13.306 .750,00$ & $13.350 .649,10$ & $16.582 .265,80$ & $16.488 .512,50$ \\
Tlogolele & $2.163 .252,27$ & $2.188 .380,68$ & $3.529 .022,73$ & $3.555 .255,68$ & $5.692 .275,00$ & $5.743 .636,36$ \\
Total & $57.878 .889,49$ & $60.988 .731,16$ & $166.019 .945,45$ & $169.169 .006,94$ & $223.898 .834,95$ & $230.157 .738,10$ \\
Rerata & $4.452 .222,27$ & $4.691 .440,86$ & $12.770 .765,03$ & $13.013 .000,53$ & $17.222 .987,30$ & $17.704 .441,39$ \\
\hline Sumberyyyyyyyyy
\end{tabular}

Sumber: Data primer diolah tahun 2014 menggunakan excel versi 2007 
Sugeng W., Sriwidodo., Irham., Jangkung H. : Dampak erupsi gunung merapi ......

Tabel 8. Nilai WTP, WTA dan Nilai Total Keberadaan TNGM Sebelum dan Setelah Erupsi Merapi

\begin{tabular}{|c|c|c|c|c|}
\hline \multirow[t]{2}{*}{ Uraian } & \multicolumn{2}{|c|}{$\begin{array}{l}\text { Nilai Rataan Potensial TNGM } \\
(\mathrm{Rp} / \mathrm{Th})\end{array}$} & \multirow[t]{2}{*}{ t-hitung } & \multirow[t]{2}{*}{ Sig } \\
\hline & Before & After & & \\
\hline Nilai WTP & $4.452 .222,27$ & $4.691 .440,86$ & $1,812 * *$ & 0,095 \\
\hline Nilai WTA & $12.770 .765,03$ & $13.013 .000,53$ & $3,282 * * *$ & 0,007 \\
\hline $\begin{array}{l}\text { Nilai Total Keberadaan } \\
\text { TNGM }\end{array}$ & $17.222 .987,30$ & $17.704 .441,39$ & $2,841 * * *$ & 0,015 \\
\hline
\end{tabular}

Sumber: Data primer diolah tahun 2014 dengan menggunakan SPSS versi 20

Keterangan: $* * *=$ signifikan pada $\alpha: 1 \%$, dan $* *$ signifikan pada $\alpha: 5 \%$

t-tabel pada $\alpha: 10 \%=2,6809 ; \alpha: 5 \%=1,7822 ;$ dan pada $\alpha: 1 \%=1,3562$

Tabel 9. Nilai Ekonomi Total (TEV) Kawasan Hutan Lindung TNGM Sebelum dan Setelah Erupsi Merapi

\begin{tabular}{|c|c|c|}
\hline \multirow[t]{2}{*}{ Nilai Manfaat } & Before Eruption & After Eruption \\
\hline & \multicolumn{2}{|c|}{---------- (Rp/TH) --------- } \\
\hline Guna langsung (direct use value) & $5.935 .742 .769,00$ & $5.456 .829 .837,00$ \\
\hline 1. Kayu bakar & $1.191 .522 .394,00$ & $988.378 .211,00$ \\
\hline 2. Rumput-rumputan & 4.074.412.769,00 & $3.865 .252 .676,00$ \\
\hline 3. Konsumsi Air & $669.807 .606,00$ & $603.198 .950,00$ \\
\hline $\begin{array}{l}\text { Guna tidak langsung (Indirect use } \\
\text { value)** }\end{array}$ & 1.510.247.377, 18 & 1.510.247.377,18 \\
\hline 1. Biodiversity & $269.707 .837,60$ & $269.707 .837,60$ \\
\hline 2. Konservasi & 1.099.247.866,08 & 1.099.247.866,08 \\
\hline 3. Carbon Storage & $141.291 .673,50$ & $141.291 .673,50$ \\
\hline Nilai Pilihan keberadaan & $223.898 .834,94$ & $230.157 .738,10$ \\
\hline $\begin{array}{l}\text { 1.WTP (Sosial budaya dan } \\
\text { kelestarian lingkungan) }\end{array}$ & $57.878 .889,49$ & $60.988 .731,16$ \\
\hline $\begin{array}{l}\text { 2. WTA (Sosial budaya dan } \\
\text { kelestarian lingkungan) }\end{array}$ & 166.019.945,45 & 169.169.006,94 \\
\hline TOTAL & $7.669 .888 .981,12$ & $7.197 .234 .952,28$ \\
\hline
\end{tabular}

Sumber : Data primer dari penjumlahan nilai guna langsung, nilai guna tidak langsung dan nilai keberadaan (2014)

Keterangan : **) Nilai guna tidak langsung dihitung pada kondisi normal.

Berdasarkan analisis tabel nilai total keberadaan TNGM yang merupakan penjumlahan dari nilai WTP dan WTA sebelum dan setelah erupsi masing-masing sebesar Rp 223.898.834,95,- dan Rp 230.157.738,10.,-

Secara statistik hasil uji $\mathrm{t}$ berbeda atau signifikan pada taraf $\alpha: 1 \%$ untuk nilai total keberadaan TNGM (Tabel 8), hal ini menunjukkan bahwa erupsi Merapi berpengaruh terhadap nilai keberadaan TNGM. Hal yang sama juga untuk nilai WTP dan WTA signifikan pada $\alpha: 5 \%$ dan $\alpha: 1 \%$, sehingga disimpulkan bahwa erupsi signifikan terhadap nilai keberadaan TNGM pada nilai WTP, WTA dan nilai total WTP dan WTA.

\section{Nilai Ekonomi Total (Total Economic Value)}

Nilai ekonomi total kawasan TNGM diperoleh dengan menjumlahkan nilai-nilai manfaat langsung (kayu bakar, rumput-rumputan dan air yang dimanfaatkan secara langsung untuk rumahtangga dan ternak), nilai manfaat tidak langsung (nilai biodiversity, konservasi dan carbon storage) serta nilai keberadaan TNGM sebelum dan setelah erupsi Merapi. Nilai ekonomi total di kawasan TNGM sebelum dan setelah erupsi masing-masing sebesar $\mathrm{Rp}$ 7.669.888.981,12 per tahun dan $\mathrm{Rp}$ 7.197.234.952,28 per tahun. Hasil perhitungan nilai ekonomi total disajikan pada Tabel 9.

\section{KESIMPULAN DAN IMPLIKASI KEBIJAKAN}

\section{Kesimpulan}

Berdasarkan hasil analisis dan pembahasan, maka dapat disimpulkan sebagai berikut: 
1. Nilai manfaat langsung (direct use value) dari keberadaan TNGM sebelum dan setelah erupsi masing-masing memberikan nilai manfaat ekonomi (economic value) sebesar $\begin{array}{lll}\mathrm{Rp} & 5.935 .742 .769,00 \quad \text { dan } \mathrm{Rp}\end{array}$ 5.456.829.837,00 meliputi komponen nilai kayu bakar, rumput-rumputan dan manfaat air untuk konsumsi rumahtangga dan ternak secara signifikan berbengaruh setelah erupsi Merapi

2. Nilai manfaat tidak langsung (indirect use value) TNGM, sebesar Rp 1.510.247.377,18 meliputi komponen nilai biodiversity, konservasi dan penyerapan karbon

3. Nilai keberadaan TNGM berdasarkan nilai total sosial budaya kearifan lokal dan kelestarian lingkungan sebelum dan setelah erupsi masing masing sebesar 223.898.834,94 dan Rp 230.157.738,10, meliputi komponen nilai WTP dan WTA berpengaruh signifikan terhadap erupsi Merapi

4. Nilai ekonomi total (Total Economic Value) kawasan TNGM sebelum dan setelah erupsi Merapi masing-masing sebesar Rp 7.669.888.981,12 dan Rp 7.197.234.952,28 per tahun.

\section{Implikasi Kebijakan}

Berdasarkan simpulan maka dapat disarankan:

1. Menjaga kelestarian Taman Nasional Gunung Merapi dengan memperlakukan secara arif dalam pemanfaatan langsung terhadap nilai ekonomi dan sosial, perlunya juga menjaga dan memperlakukan secara bijak manfaat tidak langsung pada keanekaragaman hayati (biodiversity), pengendali erosi dengan menjaga nilai konservasi dan penyerap karbon sehingga secara tidak langsung membantu terhadap penurunan karbon dalam pemanasan global.

2. Segera dilakukan perbaikan dan pembenahan kembali kawasan hutan lindung TNGM yang terkena dampak erupsi dengan langkah-langkah: pada kerusakan kawasan lahan di TNGM perlunya penanaman kembali tanaman kayu dan tanaman lain yang mendukung kelestarian TNGM dengan melibatkan langsung masyarakat untuk menanam, dan memelihara serta menjaga secara bersamasama keberadakawasan ini agar lestari, sedangkan untuk kerusakan dikawasan wisata dalam lingkungan TNGMsegera bekerjasama dengan pengelola wisata yang telah ditunjuk untuk melakukan pembenahan dan memberikan solusi dan kemudahan birokrasi dan mendorong pihak ketiga/swasta dalam pembiayaanya.

\section{DAFTAR PUSTAKA}

Anggana AF. 2011. Kajian Etnobotani Masyarakat di Sekitar Taman Nasional Gunung Merapi.Departemen Konservasi Sumberdaya Hutan dan Ekowisata Fakultas Kehutanan.Institut Pertanian Bogor. 2011.

Asmaranto, $\mathrm{R}$ dan Juwono,P.T. Analisis LajuErosi dan ArahanKonservasi di Das Pikatan, Mojokerto, Berbasis Sistem Informasi Geografis. Jurnal TEKNIK Fakultas Teknik Universitas Brawijaya, ISSN 0854-2139, Volume 14,Nomor 1 Edisi April 2007.

Badan Pusat Statistik. 2011. Yogyakarta Dalam Angka. Badan Pusat Statistik. Yogyakarta.

Balai Taman Nasional Gunung Merapi, 2001.

BBSDL. 2006. Laporan Hasil Kajian Dampak Bencana Alam (Erupsi Merapi) di DIY dan Jawa Tengah. Balai Besar Sumberdaya Lahan Bogor.Badan Penelitian dan Pengembangan Pertanian. Departemen Pertanian.Unpublished

BNPB.2011. Rencana Aksi Rehabilitasi dan Rekonstruksi Pasca Erupsi Gunung Merapi di DIY dan Jawa Tengah.Badan Nasional Penanggulangan Bencana. Jakarta. Juni 2011.Unpublished

Bishop. R.C.. and T.A. Heberlein. 1979. Measuring Values of Extramarket Goods: Are Indirect Measures Biased? American Journal of Agricultural Economics.

Dixon. John A. and Hufschmidt Maynard M. 1986.Economic Valuation Techniques for the Environmental : A case Study Workbook. The Johns Hopkins University Press. Copyright by the East 
Sugeng W., Sriwidodo., Irham., Jangkung H. : Dampak erupsi gunung merapi ......

West center. East-west environment and Policy Institute.

Fakultas Kehutanan UGM. 2002. Rencana Pengelolaan Calon Taman Nasional Gunung Merapi. Kerjasama BKSDA DI Yogyakarta dengan Fakultas Kehutanan UGM. Jogjakarta. 2002. (unpublished)

Irham. 2001.Analisis Biaya Manfaat dalam Proyek Pembangunan Berdampak Lingkungan.Enviromental Economics for Practitioners". Seminar in Applied Environmental Economics and Natural Resource Accounting. CEPI. Canora (Asia) Incorporated-CIDA Project. Montrel-Kanada

Kementrian Negara Lingkungan Hidup Republik Indonesia. 2012. Panduan Valuasi Ekonomi Ekosistem Hutan. Nomor 15 Tahun 2012. Menteri Negara Lingkungan Hidup RI. Jakarta.

Kim. C.Y. 2002.Pola Pengelolaan Hutan Tropika Berdasar pada KonsepNilai Ekonomi Total. Universitas Gajah Mada. Yogyakarta. (Disertasi).

Mantung.L..Musrizal Muin dan Suhasman. 2010.The Potency of Carbon Sink and Carbon Dioxide Absorption of Pinus Mercusii in Batualu HPT. Fakultas Kehutanan Universitas Hasanudin. Makasar.
Munasinghe. Mohan.. 1993.Enviromental Economics and Sustainable Development. The Word Bank. $1818 \mathrm{H}$ Street. N.W.. Washington. DC. USA.

Pearce. David (ed).1978.The Valuation of Social Cost.London : Allen and Unwin.

Pearce. D.W.. and R.K.. Turner. 1990. Economics of Natural Resources and the Environment. Harvester Wheatsheaf Great Britain.

Turner.K.R,Pearce D and Ian Bateman, 1994. Environmental Economics An Elementary Introduction. Centre for Social and Economic Research on the Global Environment University of East Anglia and University College London.

Sasmitawidjaja. V..2004.Valuasi Perikanan. Pariwisata. dan Perlindungan Taman Bunaken. Natural. Resources Management (NRM) Program.

Subekti Rahayu, Betha Lusiana dan Meine van Noordwijk, 2004. Pendugaan Cadangan Karbon Diatas Permukaan Tanah Pada Berbagai Sistem Penggunaan Lahan di Kabupaten Nunukan, Kalimantan Timur. Kerjasama CIDA - Care International Indonesia - World Agroforestry Centre (unpublished) www.worldagroforestry.org 